\title{
ОСОБЕННОСТИ ВЕДЕНИЯ ПАЦИЕНТОВ С ХРОНИЧЕСКОЙ ОБСТРУКТИВНОЙ БОЛЕЗНЬЮ ЛЕГКИХ И АРТЕРИАЛЬНОЙ ГИПЕРТЕНЗИЕЙ (КЛИНИЧЕСКИЙ СЛУЧАЙ)
}

\section{FEATURES OF MANAGEMENT OF PATIENTS WITH CHRONIC OBSTRUCTIVE PULMONARY DISEASE AND ARTERIAL HYPERTENSION (CLINICAL CASE)}

E. Borisova

S. Krivykh

Summary. The purpose of the analysis of this clinical case was to study the features of clinical manifestations, diagnostic studies and therapy in a patient with combined pathology: chronic obstructive pulmonary disease and arterial hypertension.

In this clinical example, the patient, against the background of such risk factors as long-term smoking experience with a smoker index of 44 pack / years, overweight, developed chronic obstructive pulmonary disease with severe symptoms (mMRS $>2$ ), with frequent exacerbations ( 2 or more in year), complicated by respiratory failure of the 1st degree (Sp02 93\%). Risk factors for the development of arterial hypertension were smoking, overweight, low high-density lipoprotein cholesterol, and hereditary predisposition. A patient with target organ lesions has initial manifestations of left ventricular hypertrophy, hypertensive retinal angiopathy and stage 2 of chronic kidney disease, and complications of discirculatory encephalopathy manifestations. An additional factor that contributed to the increase in blood pressure was the use of non-steroidal anti-inflammatory drugs for pain in the spinal column.

In the treatment, according to national guidelines, a combination of antihypertensive therapy and a combination of two long-acting inhaled bronchodilators were carried out.

Keywords: chronic obstructive pulmonary disease, arterial hypertension, comorbid pathology, diagnosis, treatment.

\author{
Борисова Екатерина Петровна \\ К.м.н., дочент, ФГАОУ ВО «Северо-Восточный \\ Федеральный университет имени М.К. Аммосова» \\ borisovaep75@mail.ru \\ Кривых Сардана Кирилловна \\ Ординатор, ФГАОУ ВО «Северо-Восточный \\ Федеральный университет имени М.К. Аммосова» \\ krivoker@mail.ru
}

Аннотация. Целью анализа данного клинического случая явилось изучение особенностей клинических проявлений, диагностических исследований и терапии у пациента с сочетанной патологией: хроническая обструктивная болезнь легких и артериальная гипертензия.

В данном клиническом примере у пациента на фоне таких факторов риска как, длительный стаж курения с индексом курильщика 44 пачка/лет, наличие избыточной массы тела развилась хроническая обструктивная болезнь легких с выраженными симптомами (mMRS>2), с частыми обострениями (2 и более в год), осложнившаяся дыхательной недостаточностью 1 степени (Sp0 293\%). Факторами риска развития артериальной гипертонии явились курение, избыточная масса тела, низкий уровень холестерина липопротеидов высокой плотности и наследственная предрасположенность. У пациента из поражений органов мишеней имеются начальные проявления гипертрофии левого желудочка, гипертоническая ангиопатия сетчатки и 2 стадия хронической болезни почек, а из осложнений проявления дисциркуляторной энцефалопатии. Дополнительным фактором, способствовавшим повышению уровня АД, явился прием нестероидных противовоспалительных препаратов (НПВП), по поводу болевого синдрома в позвоночном столбе.

В лечении, согласно национальным рекомендациям, проводилась комбинированная антигипертензивная терапия и комбинация двух длительно действующих бронхолитиков ингаляционно.

Ключевые слова: хроническая обструктивная болезнь легких, артериальная гипертензия, коморбидная патология, диагностика, лечение.

Представления о ХОБЛ в последние десятилетия подверглись коренному пересмотру. В настоящее время ХОБЛ рассматривается как заболевание с системными проявлениям и коморбидность является составной частью патологии. Наиболее часто встречается и прогностически неблагоприятно сочетание ХОБЛ и сердечно-сосудистых заболеваний, со значительным преобладанием АГ в их структуре $[1,2,3]$. 
Артериальная гипертензия составляет более 50\% всех случаев коморбидной патологии у больных ХОБЛ. Echave J.M. и соавторы провели исследование по изучению частоты встречаемости сопутствующих заболеваний у больных ХОБЛ. Было изучено 977 человек, со средним возрастом 70,1土9,8 года и получен результат, что в 65,7\% было сочетание ХОБЛ с другими патологиями, из них в 57,7\% случаев - с артериальной гипертензией $[4,5]$.

По данным крупномасштабного исследования ЭССЕ-РФ было подтверждено, что ХОБЛ и АГ имеют одинаковые предсуществующие факторы риска: курение, неправильное питание, малоподвижный образ жизни, ожирение [6]. При сочетании ХОБЛ и АГ происходит суммарное увеличение как общего, так и сердечно-сосудистых рисков, что в конечном итоге приводит к значительному ухудшению прогноза у пациентов с коморбидной патологией $[7,8]$. Артериальная гипертензия при ХОБЛ также имеет свои особенности, такие как преобладающая гипертензия в ночное время по типу «non-dippers, night-peakers» и высокая суточная вариабельность показателей АД, что способствует раннему поражению органов мишеней и развитию сердечно-сосудистых осложнений $[9,10]$.

Таким образом, адекватное ведение пациентов с коморбидной патологией, достижение целевых уровней артериального давления, снижение числа обострений и улучшение качества жизни является актуальной задачей для клинициста, что приведет к снижению уровня смертности как от сердечно-сосудистых, так и от бронхолегочных заболеваний.

\section{Цель исслеАования}

Изучить клинические проявления, особенности терапии хронической обструктивной болезни легких и артериальной гипертензии на конкретном клиническом примере пациента с данной сочетанной патологией.

\section{Материал и методы исслеАования}

Представлен клинический случай пациента И., 62 лет, находившегося на обследовании и лечении в терапевтическом отделении Республиканской больницы № 1 - Национального центра медицины. Пациенту проведено стандартное обследование, в соответствии с Клиническими рекомендациями Российского научного медицинского общества терапевтов по диагностика и лечение пациентов с хронической обструктивной болезнью легких и артериальной гипертензией [1].

\section{Результаты исслеАования \\ и их обсужАение}

Пациент И., 62 лет, поступил с жалобами на сухой кашель с трудноотделяемой мокротой, одышку при физической нагрузке средней интенсивности, повышение артериального давления (АД) с максимумом до 180/90 мм.рт.ст, головные боли, периодически головокружение, шаткость при ходьбе, шум в ушах, чувство стеснения в грудной клетке, изжогу, отрыжку после приема пищи, ноющие боли в шейной, грудной области позвоночника, усиливающиеся при движении.

Из анамнеза известно, что мужчина на пенсии, не работает. Ранее работал электриком. Проживает в г. Якутске, с женой в квартире в деревянном доме. Со слов наследственность отягощена по артериальной гипертензии, инфаркт миокарда у матери пациента, в возрасте после 65 лет.

Артериальное давление повышается в течении четырех лет с максимальными цифрами до 180/90 мм. рт.ст., при этом адаптированное АД составляет 120130/80-70 мм.рт.ст. Антигипертензивная терапия проводится препаратом «Энап» в дозе 5 мгв сутки, на фоне которого отмечает появление кашля, АД со слов контролирует. Инфаркт миокарда, острое нарушение мозгового кровообращения, сахарный диабет, язвенную болезнь, бронхиальную астму отрицает. Синкопе, синкопальных состояний не было.

Курит с 18 лет, по 1 пачке в день, индекс курильщика составляет 44 пачка/лет. ХОБЛ диагностирована 6 лет назад, когда стал отмечать общую слабость, кашель с мокротой, одышку при физической нагрузке. Обострения отмечает 2 раза в год, базисной терапии не получает.

Постоянно принимает нестероидные противовоспалительные препараты (НПВП): Диклофенак, Кеторол per os по поводу болевого синдрома в области позвоночника. Настоящее ухудшение около 10 дней, когда наросли вышеуказанные жалобы. Обследовался в поликлинике, где по рентгенографии органов грудной клетки выявлены рентген - признаки хронического бронхита, пневмосклероз. В общем анализе крови лейкоциты 9,83*10^9 л, нейтрофилы 81,8\%, СОЭ 18 мм/ч.

\section{Объективный статус}

Общее состояние пациента расценено как средней степени тяжести. В ясном сознании. Нормостенического телосложения. Индекс массы тела (ИМТ) 29,4 кг/ м². Температура тела 37,2 С. Кожные покровы обычной окраски, эластичные, умеренной влажности. Форма 
грудной клетки бочкообразная, симметричность сохранена. При пальпации грудная клетка ригидна. Смешанный тип дыхания с ЧДД 20 в минуту, SpO2 = 93\%. Пальпация грудной клетки безболезненна. При перкуссии перкуторный звук коробочный. Экскурсия нижнего края лёгких снижена. Дыхание жесткое, рассеянные свистящие хрипы по всем полям, выслушиваемые при кашле.

Патологических пульсаций в эпигастральной области, в яремной ямке и в области сосудов шеи не наблюдается. В области сердца сердечного горба не выявлено. Верхушечный толчок визуально не определяется. чСС 95 ударов в минуту. Частота пульса 95 ударов в минуту. Тоны сердца приглушенные, ритмичные. АД 170/90 мм. рт.ст. на обеих руках. При осмотре ротовой полости язык влажный, умеренно обложен белым налетом. Зев не гиперемирован, миндалины не увеличены. Живот без особенностей, при пальпации мягкий, безболезненный. Размеры печени в норме. Стул оформленный, регулярный. При осмотре область поясницы без изменений. Симптом поколачивания отрицательный с обеих сторон.

\section{^абораторные и инструментальные исслеАОвания}

Общий анализ крови: Эритроциты 4,64*10^12 л, гемоглобин 125 г/л, гематокрит 43,0, лейкоциты $7,88 * 10 \wedge 9$ л, тромбоциты $284 * 10 \wedge 9$ л, эозинофилы 0,10\%, лимфоциты 0,95\%, базофилы 0,02\%, моноциты 7,7\%, нейтрофилы 6,21\%.

Общий анализ мочи: без патологических отклонений.

Электролиты крови: калий 4,14 ммоль/л; натрий 137,0 ммоль/л.

Биохимическое исследование крови: общий белок 65,3 г/л, альбумин 32 г/л, билирубин общий 8,5 мкмоль/л, билирубин прямой 2,3 мкмоль/л, щелочная фосфатаза 64,4 ед/л, АСТ 19,4 ед/л, АЛТ 12 ед/л, холестерин 3,4 ммоль/л, липопротеиды низкой плотности 2,1 ммоль/л, липопротеиды высокой плотности 0,6 ммоль/л, глюкоза 4,0 ммоль/л, мочевина 4,9 ммоль/л, креатинин 91,3 мкмоль/л.

\section{СКФ: 77 мл/ми1,73м² CKD-EPI.}

Исследование системы гемостаза: МНО 1,28, пТВ 81 сек, фибриноген 4,0 мкмоль/л, АЧТВ 20 сек.

Клинический анализ мокроты: слизисто-гнойная, вязкая, альвеолярные клетки 2-1-3, лейкоциты 10-7-9, эритроциты 2-2-1, эпителий плоский 0-1-1.
Диагностика хеликобактерной инфекичи - антитела к антигену CagA Helicobacter pylori (экспресс): отрицательный.

Спирография. Заключение: Нарушение вентиляционной способности легких по смешанному типу с преобладанием обструктивных нарушений тяжелой степеНИ тяЖестИ. ФЖЕЛ 59\%; ОФВ $138 \%$ ОФВ $/$ ФЖЕЛ 65\%.

\section{УЗИ сердца с цветным \\ допплеровским картированием.}

Заключение: Глобальная сократимость миокарда левого желудочка сохранена. Фракция выброса-61\%. Грубых четких зон локального гипокинеза на момент осмотра достоверно не выявлено. Уплотнение створок аортального и митрального клапанов. Регургитация на клапане легочной артерии 1 ст. Эхо-признаки пролапса митрального клапана 1 ст. с минимальной регургитацией. Полости сердца не расширены. Начальные признаки гипертрофии левого желудочка.

ЭКГ: Ритм синусовый с чСС 90 в мин. Электрическая ось сердца отклонена влево. Определяются нарушение внутрижелудочковой проводимости по правой ножке пучка Гиса и метаболические изменения миокарда.

\section{УзИ органов брюшной полости.}

Заключение: Диффузные изменения паренхимы поджелудочной железы. Деформация желчного пузыря. Уплотнение почечных синусов.

\section{Холтеровское мониторирование ЭКГ.}

Заключение: динамика ЧСС в течение всех суток в пределах возрастной нормы. Циркадный индекс ригидный. В течение всего периода мониторирования ритм синусовый. Желудочковая эктопическая активность в норме, представлена редкими одиночными монотопными желудочковыми экстрасистолами (17), в дневное и ночное время, град. 1 по Ryan. Наджелудочковая эктопическая активность в норме, представлена редкими одиночными предсердными экстрасистолами (60), в дневное и ночное время. Паузы не зарегистрированы. Интервал PQ, интервал QT в пределах нормы. Эпизодов ишемии не выявлено.

ФЭГДС Заключение: недостаточность кардии, рефлюкс-эзофагит. Смешанный гастрит. Эрозия антрального отдела. Дуоденит.

\section{Рентгенография позвоночника.}

Заключение: Остеохондроз шейного отдела позвоночника, более выраженный в сегментах C5-6, С6-7. 
Рентген-признаки спондилоартроза, унковертебрального артроза шейного отдела позвоночника. Деформирующий спондилез в сегменте C5-6.

Рентгенография грудной клетки. Заключение: Рентген-признаки хронического бронхита.

\section{Консультации специалистов.}

Врач-офтальмолог. Диагноз: Пресбиопия. Ангиопатия сетчатки по гипертоническому типу.

\section{Клинический диагноз}

Основное заболевание:

1. Хроническая обструктивная болезнь легких, тяжелая степень тяжести нарушения бронхиальной проходимости (GOLD3), бронхитический тип, группа «Д» с выраженными симптомами (mMRS >2), с частыми обострениями (2 в год).

2. Гипертоническая болезнь 2 стадии. Неконтролируемая артериальная гипертензия. Гипертрофия левого желудочка. Дислипидемия. Риск CСО 4 (очень высокий). Целевой уровень АД $<130 / 80$ мм.рт.ст.

Осложнение основного заболевания:

1. Гипоксемическая дыхательная недостаточность 1 степени.

2. Дисциркуляторная энцефалопатия на фоне артериальной гипертензии.

3. Хроническая болезнь почек 2 стадия с СКФ 77 мл/ми1,73м² по CKD-EPI.

\section{Сопутствующий диагноз:}

Атеросклероз аортального и митрального клапанов. Регургитация на клапане легочной артерии 1 степени.

Пролапс митрального клапана с минимальной регургитацией.

НПВП-ассоциированный эрозивный гастрит. Гастроэзофагеальная рефлюксная болезнь. Неэрозивный рефлюкс-эзофагит. Дуоденит.

Остеохондроз шейного и грудного отделов позвоночника.

\section{Лечение.}

Немедикаментозная терапия. Проведена беседа о необходимости отказа от курения, что приведет с течением времени как к улучшению функции легких, так и снижению уровня АД, что будет способствовать снижению доз антигипертензивных препаратов. Также проведена беседа о диетических рекомендациях, таких как снижение количества потребляемой соли до 5 грамм в сутки, увеличение в рационе питания полиненасыщенных жирных кислот, клетчатки, необходимости ежедневной аэробной физической нагрузки не менее 30 минут в день.

\section{Медикаментозно:}

Т. Азилсартана медоксомил+хлорталидон 40 мг+ 12,5 мг 1 раз в день утром на постоянной основе с контролем АД; Т. Пантопразол по 20 мг 2 раза в день за 30 минут до еды в течении 14 дней; Гликопиррония бромид + Индакатерол 50+110 мкг вдыхать 1 раз в день утром на постоянной основе (базисная терапия); Ипратропия бромид + Фенотерол ингаляции через дозированный аэрозольный ингалятор со спейсером по потребности; Ацетилцистеин 200 мг 3 раза в день; Т. Аторвастатин 40 мг 1 раз вечером постоянно.

К выписке из стационара у пациента достигнут целевой уровень АД - 120/80 мм.рт.ст., купирован кашель, уменьшилась одышка.

При выписке даны рекомендации по немедикаментозной терапии (физическая активность, диета, вакцинация от гриппа и пневмококковой инфекции) и медикаментозной терапии препаратами, подобранными в стационаре.

\section{Зак^ючение}

В данном клиническом примере у пациента на фоне таких факторов риска как, длительный стаж курения с индексом курильщика 44 пачка/лет, наличие избыточной массы тела развилась хроническая обструктивная болезнь легких с выраженными симптомами (mMRS>2), с частыми обострениями (2 и более в год), осложнившаяся дыхательной недостаточностью 1 степени (SpO 2 93\%). Факторами риска развития артериальной гипертонии также явились курение, избыточная масса тела, низкий уровень холестерина липопротеидов высокой плотности и наследственная предрасположенность. Дополнительным фактором, способствовавшим повышению уровня АД, явился прием НПВП, по поводу болевого синдрома в позвоночнике.

Пациенту были проведены диагностические обследования, направленные как на выяснение степени поражения органов мишеней, так и на определение функции легких. Из поражений органов мишеней имеются начальные проявления гипертрофии левого желудочка, ангиопатия сосудов сетчатки и 2 стадия хронической болезни почек, из осложнений проявления дисциркуляторной энцефалопатии (головные боли, головокружение, шум в ушах). 
В лечении, согласно национальным рекомендациям, проводилась комбинированная антигипертензивная терапия и комбинация двух длительно действующих бронхолитиков ингаляционно. У пациента на прием Энапа, препарата из группы ингибиторов ангиотензинпревращающего фермента, отмечался часто встречающийся при этом побочный эффект - кашель, поэтому был назначен препарат из группы блокаторов рецептора ангиотензина II - азилсартана медоксомил. Рекомендованные, особенно при сочетании ХОБЛ и АГ, препараты из группы блокаторов кальциевых каналов не были назначены ввиду наличия у пациента недостаточности кардии, рефлюкс-эзофагита. Вторым компонентом комбинированной антигипертензивной терапии был назначен диуретик Хлорталидон, как препарат, позволяющий эффективно контролировать ночное АД, а также снижать смертность от сердечно-сосудистых заболеваний, а как мы помним особенностью течения АГ при ХОБЛ является преобладающая гиперетензия В ночное время по типу «non-dippers, night-peakers» и высокая суточная вариабельность показателей АД. У данного пациента уровень калия крови в норме и совместное назначение с ингибитором ренинангиотезиновой системы будет предотвращать развития гипокалиемии, в сравнении с монотерапией тиаздным диуретиком.
Таким образом, можно сформулировать следующие общие рекомендации по ведению больных ХОБЛ в сочетании АГ, так как сочетание этих двух патологий приводит к взаимному отягощению клинических проявлений и повышенной нагрузки на кардио-респираторную систему:

- проводить коррекцию факторов риска, общих для ХОБЛ и АГ (курение, избыточная масса тела, гиподинамия);

- стратифицировать факторы риска;

- своевременно купировать обострения ХОБЛ;

- мониторировать пиковую скорость выдоха пикфлоуметром при использовании $\beta$-адреноблокаторов, ингибиторов ангиотензинпревращающего фермента, НПВП;

- проводить адекватную базисную терапию ХОБЛ для улучшения качества жизни и уменьшения рисков обострения;

- осуществлять выбор антигипертензивных препаратов с учетом конкретной клинической ситуации;

- мониторировать эффективность и переносимость назначенной терапии;

- назначать комбинацию антигипертензивынх препаратов с доказанной эффективностью у больных ХОБЛ.

\section{ЛИТЕРАТУРА}

1. Малявин А.Г., Мартынов А.И., Адашева Т.В. и др. Диагностика и лечение пациентов с хронической обструктивной болезнью легких и артериальной гипертензией. Клинические рекомендации РНМОТ. Терапия. 2019. Т. 5. № 31. Приложение:1-57.

2. Vogelmeier C.F., Criner G.J., Martinez F.J. et al. Global strategy for the diagnosis, management, and prevention of chronic obstructive lung disease 2017 report: GOLD executive summary. Am J Respir Crit Care Med. 2017. vol. 195. no. 5. P. 557-582.

3. Greulich T., Weist B.J.D., Koczulla A.R. et al. Prevalence of comorbidities in COPD patients by disease severity in a German population. Respir Med. 2017. vol. 132. P. $132-138$.

4. Hill K., Goldstein R.S., Guyatt G.H. et al. Prevalence and underdiagnosis of chronic obstructive pulmonary disease among patients at risk in primary care. CMAJ. 2010. vol. 182. P. 673-678.

5. Echave J.M., Casanova L.C., Cosio B.G. et al. Comorbidity in chronic obstructive pulmonary disease. Related to disease severity? Int J Chron Obstruct Pulmon Dis. 2014. Vol. 9. P. 1307-1314.

6. Муромцева Г.А., Концевая А.В., Константинов В.В. и др. Распространенность факторов риска неинфекционных заболеваний в российской популяции в 2012-2013 гг. Результаты исследования ЭССЕ-РФ // Кардиоваскулярная терапия и профилактика. 2014. Т. 13. № 6. С. 4-11.

7. Divo M., Cote C., de Torres J.P., Casanova C. et al. Comorbidities and risk of mortality in patients with chronic obstructive pulmonary disease. Am J Respir Crit Care Med. 2012. vol. 186. no. 2. P. 155-61.

8. Brassington K., Selemidis S., Bozinovski S. et al. New frontiers in the treatment of comorbid cardiovascular disease in chronic obstructive pulmonary disease. Clin Sci (Lond). 2019. vol.133. no. 7. P. 885-904.

9. Бородкин А.В., Кароли Н.А., Ребров А.П. Суточный профиль артериальной ригидности у пациентов с хронической обструктивной болезнью легких и хронической сердечной недостаточностью // Клиницист. 2015. Т. 9. № 3. С. 40-45.

10. Чазова И.Е., Невзорова В.А., Амбатьелло Л.Г. и др. Клинические рекомендации по диагностике и лечению пациентов с артериальной гипертонией и хронической обструктивной болезнью легких // Системные гипертензии. 2020. Т. 17. № 3. С.7-34. 